\title{
Collagen metabolism in folic acid deficiency
}

\author{
By J. G. A. J. HAUTVAST* aND M. J. BARNES $\dagger$ \\ MRC Dunn Nutrition Unit, Dunn Nutritional Laboratory, University of Cambridge \\ and Medical Research Council, Milton Road, Cambridge
}

(Received 24 January 1974 - Accepted 7 March 1974)

\begin{abstract}
I. The effect of folic acid deficiency on collagen formation, with respect to the level of collagen-protein synthesis and the extent of collagen-proline hydroxylation, has been studied. A folic acid-free diet containing to $\mathrm{g}$ sulphasuxidine $/ \mathrm{kg}$ was used to induce folate deficiency in young male rats. Animals were judged folic acid-deficient on the grounds of retardation of growth, characteristic haematological changes and the urinary excretion of formimino-L-glutamic acid.

2. From isotope incorporation studies it was found that folic acid deficiency caused a marked impairment in collagen synthesis. It was shown, however, from the use of pair-fed control animals, that this was due in part to a reduced food intake accompanying the vitamin deficiency. The further reduction in synthesis in addition to that attributable to inanition was considered to arise from an involvement of folic acid in general protein synthesis, since it was found that the synthesis of elastin and non-collagenous skin proteins was similarly impaired.

3. Reduced synthesis of collagen was not considered attributable to lack of hydroxylation of peptidyl proline that may occur in ascorbic acid deficiency. Hydroxylation of collagen-and elastin-proline was only very slightly impaired in folic acid deficiency. It was concluded that, at least when ascorbic acid is present, folic acid is not directly essential for the hydroxylation, in vivo, of peptidyl proline. The results support the view that ascorbic acid participates direct, in vivo, in this hydroxylation rather than indirect by simply maintaining an adequate level of reduced folates. They do not, however, exclude the possibility, arising from the known ability of tetrahydrofolate to participate in the hydroxylation of collagen proline in vitro, that when both ascorbate and folate are present, the latter may, in some measure, share in the role of reducing agent in the hydroxylation of peptidyl proline in vivo.
\end{abstract}

Collagen hydroxyproline and hydroxylysine are derived by the enzymic hydroxylation of the pertinent prolyl and lysyl residues previously incorporated into peptide linkages during collagen biosynthesis. The hydroxylation requires molecular oxygen, ferrous ion, ascorbic acid and $\alpha$-ketoglutarate. The latter compound can be regarded as the co-substrate in the mixed-function oxidation reaction and undergoes a stoichiometric decarboxylation to succinate during the course of hydroxylation (Prockop, 1970; Udenfriend, 1970). With these co-factor requirements collagen proline and collagen lysine hydroxylases can be considered as members of a class of hydroxylases, all of which require for activity molecular oxygen, ferrous ion, a 2-keto acid and a reducing agent. The role of the latter in the hydroxylation reaction has yet to be fully elucidated (see Barnes \& Kodicek, 1972).

Although the requirement for ferrous ion and $\alpha$-ketoglutarate is specific, the participation of ascorbic acid in the hydroxylation of collagen proline and lysine is not obligatory and, at least in the cell-free system, tetrahydrofolate, for example, or the related unconjugated pteridine 2-amino-4-hydroxy-6,7-dimethyl-tetrahydropteridine

* Present address: Agricultural University, Department of Human Nutrition, Wageningen, The Netherlands.

+ Present address and for reprints: Department of Pathology, University of Cambridge, Tennis Court Road, Cambridge. 
can substitute in some measure for ascorbic acid (Hutton, Tappel \& Udenfriend, 1967 ). Priest \& Bublitz (1967) have also reported that the synthesis of hydroxyproline by $3^{\text {T }} 6$ mouse fibroblasts in cell culture was stimulated equally by addition of ascorbic acid or 6,7-dimethyl-tetrahydropteridine. Reduced pteridines are known co-factors in a number of hydroxylations, for example in the hydroxylation of phenylalanine, tyrosine and tryptophan (see Ikeda, Fahien \& Udenfriend, 1966; Kaufman, 197I; Lovenberg, Bensinger, Jackson \& Daly, x971; Shiota, 1971).

Gould (1970) has reported a marked reduction in the formation of collagen, as measured by the formation of peptide-bound hydroxyproline, both in rats made folic acid-deficient with the folic acid antagonist methotrexate and in guinea-pigs rendered folic acid-deficient by the use of a folic acid-free diet. In view of the unknown specificity, in vivo, of ascorbic acid as a reducing agent in the hydroxylation of collagen proline and lysine, and the known ability of reduced pteridines to participate in biological hydroxylations, we decided to examine the nature of the impairment in collagen synthesis in folic acid deficiency and in particular to determine whether the reduced formation of hydroxyproline might reflect impaired hydroxylation of collagen proline rather than (or in addition to) reduced collagen-protein synthesis. Formation of underhydroxylated collagen would imply an effective involvement of folic acid (or related compounds) in vivo in the hydroxylation of collagen proline even in the presence of normal levels of ascorbic acid.

The synthesis of elastin, which also contains some hydroxyproline, although at a much lower level than in collagen, was also studied as an additional means of assessing the effect of a deficiency of folic acid on the hydroxylation of peptidyl proline.

A preliminary account of this work has already been presented (Hautvast \& Barnes, 1972).

\section{MATERIALS AND METHODS}

Radioactive amino acids. $\mathrm{L}-\left[\mathrm{G}-{ }^{3} \mathrm{H}\right]$ proline, $690 \mathrm{mCi} / \mathrm{mmol}$, was obtained as an aqueous solution ( $\mathrm{I} \mathrm{mCi} / \mathrm{ml}$ ) from the Radiochemical Centre, Amersham, Bucks.

Collagenase. This was highly purified collagenase (CLSPA) from Worthington Biochemical Corp, Freehold, New Jersey, USA, reported by the suppliers to be free of nonspecific proteolytic activity. No reaction, as judged by ninhydrin assay of the incubation mixture, could be detected by us with bovine plasma albumin as substrate.

Dialysis tubing. Visking $18 / 32$ dialysis tubing, which is reported to retain completely insulin of molecular weight 6000 (Craig, King \& Stracher, 1957), was used.

Diets. The basic folic acid-free diet was similar to that described by Kodicek \& Carpenter (I950), with the following composition $(\mathrm{g} / \mathrm{kg}$ ): casein (vitamin-free), $\mathrm{I} 80$; sucrose, $73^{\circ}$; cottonseed oil, 30 ; salt mixture (composition given below), $5^{\circ}$; sulphasuxidine (to inhibit the growth of the intestinal flora), 10. The diet also contained $(/ \mathrm{kg})$ : L-cystine, $1 \cdot 5 \mathrm{~g}$; choline chloride, $2 \mathrm{~g}$; calcium D-pantothenate, $20 \mathrm{mg}$; thiamin hydrochloride, $3 \mathrm{mg}$; pyridoxine hydrochloride, $3 \mathrm{mg}$; riboflavin, $3 \mathrm{mg}$; nicotinamide, $25 \mathrm{mg}$; biotin, $0 . \mathrm{Img}$ and cyanocobalamin $0.05 \mathrm{mg}$. The salt mixture contained $(\mathrm{g} / \mathrm{kg})$ : calcium carbonate, 205; calcium hydrogen phosphate, 325 ; disodium hydrogen 
phosphate, 185 ; potassium chloride, 205; magnesium sulphate, 70; manganese sulphate, 4.5 ; ferric citrate, 4.35 ; copper sulphate, 0.375 ; zinc carbonate, 0.75 ; potassium iodate, 0.025 . Each animal also received orally, once a week: $D L-\alpha$-tocopheryl acetate $2 \mathrm{mg}$, retinyl acetate $344 \mu \mathrm{g}$, ergocalciferol $5 \mu \mathrm{g}$ and 2-methyl-r,4-naphthoquinone $50 \mu \mathrm{g}$.

Young male rats (black-and-white hooded) weighing $55^{-60} \mathrm{~g}$, were divided into five groups. The folic acid-deficient group (group 5) received ad lib. the basic diet (containing Io g sulphasuxidine/kg). One control group (group I) received ad lib. the basic diet from which the sulphasuxidine was omitted. Animals in group 2 received the same diet as those in group I but were pair-fed (as a group) against the animals of group 5. A further control group (group 3) received ad lib. the basic diet and in addition were given orally, three times weekly, $40 \mu \mathrm{g}$ folic acid. Group 4 was treated as group 3 but was pair-fed against group 5. Body-weight was recorded three times weekly. Pair feeding commenced at day 14.

Blood analyses. Blood samples were initially collected by cardiac puncture. After

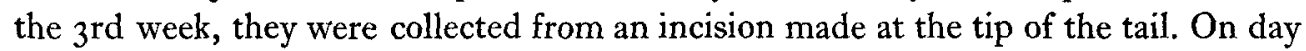
42 , blood was collected from the vena cava immediately after killing the animals.

Haemoglobin was estimated by the alkaline haematin method (Clegg \& King, 1942). The packed cell volume (PCV) was obtained using heparinized micro-haematocrit tubes. The red blood cell count (RBCC) was measured with a Neubauer counting chamber, with Hayem's solution as the diluting medium. Similarly the white cell count (WBCC) was determined after dilution with Turk's solution. The differential white cell count was determined from a blood film treated with Leishman stain.

Excretion of formimino-L-glutamic acid (FIGlu). FIGlu in the urine was determined colorimetrically using the alkaline ferricyanide-nitroprusside reaction as described by Tabor \& Wyngarden (1958). The animals were placed singly in metabolism cages to permit the collection of urine free from faeces. Animals had access to drinkingwater but not food. Urine samples were collected for $7 \mathrm{~h}$ into $0.2 \mathrm{ml} \mathrm{O} . \mathrm{I} \mathrm{M}-\mathrm{HCl}$.

Determination of hydroxyproline. In some instances hydroxyproline in hydrolysates was estimated colorimetrically by the procedure of Bergman \& Loxley ( 1963 ).

Preparation of dorsal skin collagen. The dorsal skin of each animal was shaved prior to killing. On day 42 each animal received by intraperitoneal injection $0.2 \mathrm{mCi} \mathrm{L-}$ $\left[\mathrm{G}-{ }^{3} \mathrm{H}\right]$ proline/100 $\mathrm{g}$ body-weight. After $5 \mathrm{~h}$ the animals were killed by diethyl ether anaesthesia. A portion of dorsal skin was removed, scraped free of epidermis and subcutaneous tissue, and a sample then combined with an equal weight of sample from each of the other animals within the same experimental group. The dorsal skin samples from the six animals in group 5 were combined into two sets of three, designated groups $5 \mathrm{a}$ and $5 \mathrm{~b}$. The wet weight of combined skin samples for each group was $\mathrm{I} g$. Combined skin samples were disintegrated and extracted with hot trichloroacetic acid to solubilize collagen as previously described (Barnes, Constable, Morton \& Kodicek, 1970). Extracts were dialysed exhaustively against large volumes of water, initially containing excess unlabelled proline and hydroxyproline, and then freeze-dried. A sample of the freeze-dried material was digested with collagenase and the collagenderived diffusible products obtained by this procedure collected by dialysis (Barnes 
et al. 1970). The diffusate was hydrolysed by refluxing under nitrogen with $6 \mathrm{M}-\mathrm{HCl}$ for $24 \mathrm{~h}$, and the specific activities of proline and hydroxyproline in the hydrolysate determined as described below.

Preparation of aortic elastin. The aorta was removed from each animal, as far as the bifurcation. Aortae were combined within each group. As already indicated the six animals in group 5 were subdivided into two groups of three, designated groups 5 a and $5 \mathrm{~b}$. Aortic elastin was isolated and hydrolysed by the method described by Barnes, Constable \& Kodicek ( 1969 ). The specific activities of proline and hydroxyproline in hydrolysates were determined as described below.

Non-collagenous proteins of skin. The insoluble residue remaining after hot trichloroacetic-acid extraction of dorsal skin was regarded as representing the non-collagenous protein fraction of skin. The residue was washed with cold water to remove residual trichloroacetic acid and was then freeze-dried. A sample of the freeze-dried preparation was hydrolysed by refluxing under $\mathrm{N}_{2}$ with $6 \mathrm{M}-\mathrm{HCl}$ for $24 \mathrm{~h} . \mathrm{HCl}$ was removed by rotary evaporation under reduced pressure. The hydrolysate was dissolved in water and the radioactivity in a portion of hydrolysate was determined in $10 \mathrm{ml}$ of Kennedy's ( 1969 ) solution using a Beckman liquid scintillation spectrometer (model LS-250, Beckman Instruments Ltd, Croydon CR9 3 LG).

Hydroxyproline in the hydrolysate was estimated colorimetrically by the procedure of Bergman \& Loxley ( $196_{3}$ ). The specific activity of proline in the hydrolysate was determined as described below.

Determination of the specific activities of proline and hydroxyproline in protein hydrolysates. $\mathrm{HCl}$ was removed from hydrolysates by rotary evaporation under reduced pressure. Proline and hydroxyproline in the hydrolysate were separated by ionexchange chromatography, estimated and the radioactivity of each counted and specific activities calculated by the method described by Barnes et al. (1969). Results were corrected to a uniform efficiency of counting (30\%).

\section{RESULTS}

Folic acid status. Details of the different experimental groups are given in Table $\mathbf{I}$. Animals in group 5, receiving the basal folic acid-free diet containing $10 \mathrm{~g}$ sulphasuxidine $/ \mathrm{kg}$, were judged folic acid-deficient on the grounds of retardation in growth, characteristic haematological changes and the appearance of FIGlu in the urine.

Mean growth curves are shown in Fig. I. Animals in group 5 exhibited retardation in growth from about day ro onwards.

The haematological results are presented in Table 2. Animals in group 5 showed a decrease in haemoglobin content, a reduced red and white cell count, particularly in respect of granulocytes, and a fall in PCV, all indicative of a marked folic acid deficiency (Kodicek \& Carpenter, I950; Herbert \& Bertino, 1967; Stokstad, I968).

The existence of a folic acid deficiency in rats of group 5 was indicated also by the urinary excretion of FIGlu by these animals (Rabinowitz \& Tabor, 1958). Excretion of FIGlu was already appreciable by day $2 \mathrm{I}$ when this determination was first made. The mean FIGlu excretion ( $\pm \mathrm{SE}, \mu \mathrm{mol} / 7 \mathrm{~h}$ collection period) in group 5 was as follows: 
Table I. Details of experimental groups used to study folic acid deficiency in rats

\begin{tabular}{|c|c|c|c|c|}
\hline \multicolumn{2}{|c|}{ Group } & Diet & Feeding pattern & No. of rats/group \\
\hline \multirow[t]{4}{*}{ Control } & I & $\begin{array}{l}\text { Basic folic acid-free diet } \\
\text { omitting sulphasuxidine }\end{array}$ & $A d l i b$. & 3 \\
\hline & 2 & As $I$ & $\begin{array}{l}\text { Pair-fed against } \\
\text { the animals of } \\
\text { group } 5\end{array}$ & 3 \\
\hline & 3 & $\begin{array}{l}\text { Basic folic acid-free diet (with } \\
\text { Io g sulphasuxidine } / \mathrm{kg} \text { ) } \\
\text { plus } 40 \mu \mathrm{g} \text { folic acid orally } \\
\text { three times weekly }\end{array}$ & Ad lib. & 4 \\
\hline & 4 & As 3 & $\begin{array}{l}\text { Pair-fed against } \\
\text { the animals of } \\
\text { group } 5\end{array}$ & 4 \\
\hline Folic acid-deficient & $\begin{array}{r}5 \mathrm{a} \\
\mathrm{b}\end{array}$ & $\begin{array}{l}\text { Basic folic acid-free diet } \\
\text { containing 1o } \mathrm{g} \\
\text { sulphasuxidine } / \mathrm{kg}\end{array}$ & Ad lib. & $3\} 6$ \\
\hline
\end{tabular}

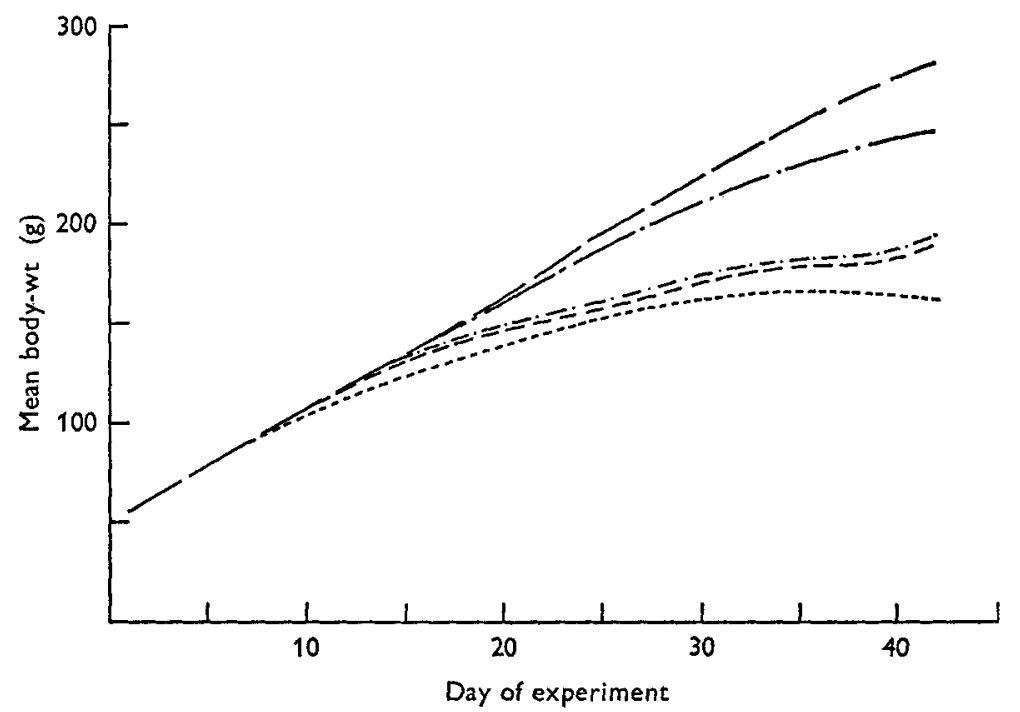

Fig. 1. Mean growth curves of rats in folic acid-deficient and control groups. - - group 1 ; -- , group $2 ;-\cdots-$, group $3 ;-.-$, group $4 ;-\cdots$ group 5 . For details of groups see Table 1 .

day $21,19 \cdot 0 \pm 0 \cdot 7$; day $28,25 \cdot 5 \pm 1 \cdot 6$; day $35,26 \cdot 6 \pm 1 \cdot 7$. The excretion of FIGlu was negligible in all control groups.

Animals were killed on day 42 since it was considered that animals in group 5 were by this time already severely folic acid-deficient. Some of these animals had begun to lose weight and prolongation of the experiment could have resulted in their loss.

Incorporation of $L-\left[G^{-3} H\right]$ proline into dorsal skin collagen. Collagen refers in this study to the non-diffusible material of skin which is extractable with hot trichloroacetic acid and which is digestible with collagenase. As judged from the hydroxyproline content, approximately $90 \%$ of the non-diffusible material extracted with hot trichloroacetic 


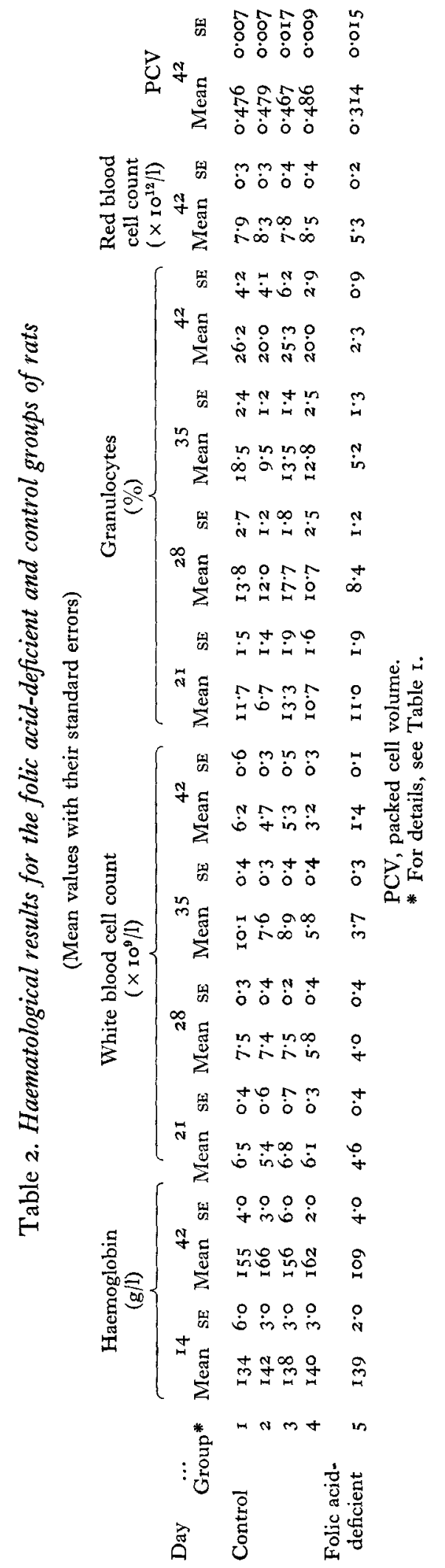


Table 3. Yield of hot trichloroacetic acid-soluble (collagenous) and -insoluble (noncollagenous) fractions ( $\mathrm{mg} / \mathrm{g}$ wet wt of skin) from the dorsal skin of folic acid-deficient and control groups of rats

\begin{tabular}{|c|c|c|c|}
\hline \multicolumn{2}{|l|}{ Group* } & $\begin{array}{l}\text { Hot trichloroacetic } \\
\text { acid-soluble fraction }\end{array}$ & $\begin{array}{l}\text { Hot trichloroacetic } \\
\text { acid-insoluble fraction }\end{array}$ \\
\hline Control & $\mathbf{I}$ & I 34 & 166 \\
\hline & 2 & I 44 & 143 \\
\hline & 3 & 132 & 148 \\
\hline & 4 & I 49 & 128 \\
\hline Folic acid-deficient & $\begin{array}{r}5 \mathrm{a} \\
\mathrm{b}\end{array}$ & $\begin{array}{l}\text { I } 96 \\
\text { I } 78\end{array}$ & $\begin{array}{r}100 \\
84\end{array}$ \\
\hline
\end{tabular}

acid was collagen. The hydroxyproline content of the insoluble residue remaining after extraction indicated that 90-95\% of the total skin collagen was extracted with hot trichloroacetic acid.

Collagen synthesis was studied by measuring the incorporation of radioactive proline into collagen isolated after the administration of $\mathrm{L}-\left[\mathrm{G}-{ }^{3} \mathrm{H}\right]$ proline. The effect of folic acid deficiency on the formation of collagen hydroxyproline was investigated by determining the specific activity ratio, collagen proline:hydroxyproline. This is normally I: $\mathrm{I}$, indicative of the fact that the newly-synthesized, labelled collagen is hydroxylated to the same extent as the unlabelled, preformed collagen isolated along with the labelled material. However, in the event of an impairment in hydroxylation and the synthesis of a collagen with a level of hydroxylation lower than that in the preexisting collagen, this ratio will increase, reaching infinity if inhibition is complete. Specific activities of collagen proline and hydroxyproline were determined in the diffusible peptides obtained by treatment of the non-diffusible, hot trichloroacetic acid-extracted material with collagenase. Approximately $90 \%$ of the hydroxyproline was rendered diffusible by this treatment. Treatment with collagenase was used to separate the proline radioactivity in collagen from any proline radioactivity from noncollagenous proteins that might be present.

The yield of non-diffusible material extracted with hot trichloroacetic acid is given in Table 3. The highest yield was obtained in the folic acid-deficient group. This may be due to dehydration of the skin if, as seems likely, these animals exhibit a reduced water intake in addition to a reduced food intake. It may also in part reflect the decreased concentration of hot trichloroacetic acid-insoluble material in the skin of these animals (see Table 3).

Specific activities of collagen proline and hydroxyproline are given in Table 4. Results for groups $I$ and 3 are very similar, which indicates that sulphasuxidine had no effect per se on collagen synthesis. In accordance with the markedly reduced rate of growth of animals in the pair-fed control groups 2 and 4 , the specific activities in these groups were much lower than in the controls fed ad lib. Thus collagen synthesis was reduced as a consequence of the inanition accompanying the vitamin deficiency. Specific activities in the folic acid-deficient group were, however, even lower than those 
Table 4. Specific radioactivities and total incorporation of radioactivity into collagen proline and hydroxyproline in folic acid-deficient and control groups of rats given, intraperitoneally, $0.2 \mathrm{mCi} \mathrm{L}-\left[\mathrm{G}-{ }^{3} \mathrm{H}\right]$ proline $/ \mathrm{IO0} \mathrm{g}$ body-wt

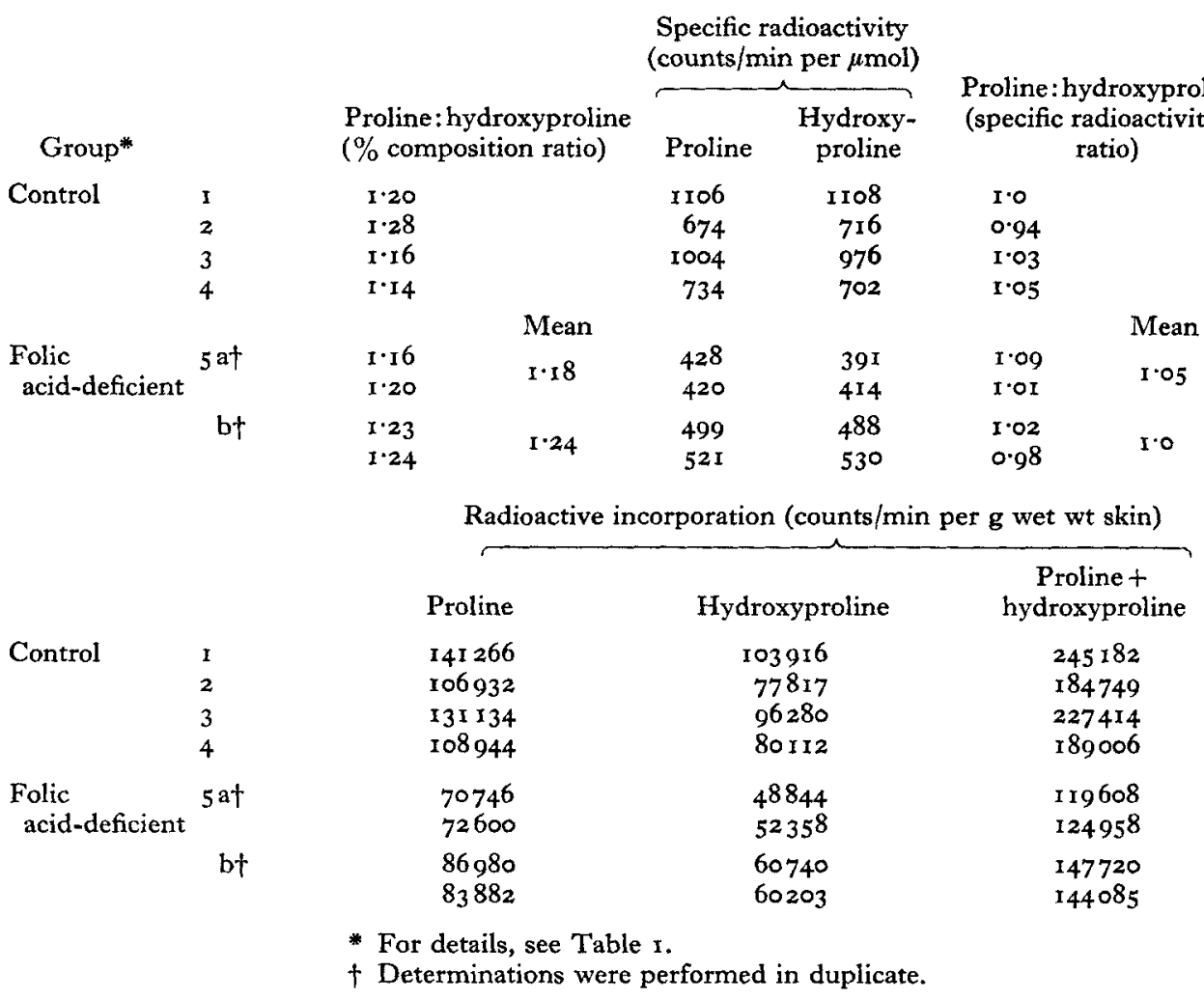

in the pair-fed control groups and this suggests a further reduction in collagen synthesis in these animals, attributable to the folic acid deficiency itself. This is borne out by the incorporation data, presented in Table 4 , where it can be seen that radioactivity incorporated into collagen per $\mathrm{g}$ skin, in the folic acid-deficient group, is less than the corresponding incorporation in the pair-fed controls, despite the higher concentration of collagen in the skin in the former group (Table 3 ).

Inspection of the proline: hydroxyproline specific radioactivity ratios indicates that values for all groups were close to unity. However, the precise value for this ratio depends upon the accuracy of the determination of proline and hydroxyproline in collagen hydrolysates. A slight error in the determination of either will cause a slight alteration in the ratio. As can be seen in Table 4, the ratio, proline:hydroxyproline (per cent composition) shows some variation. Fig. 2 shows a plot of the specific radioactivity ratio $v$. percentage composition ratio for proline:hydroxyproline. All control values fall on a straight line, in agreement with the suggestion that the slight variation from unity in the value of the specific radioactivity ratio is attributable to slight errors in the determination of proline or hydroxyproline or both. However, the two values for the folic acid-deficient group are both slightly above this line. This 


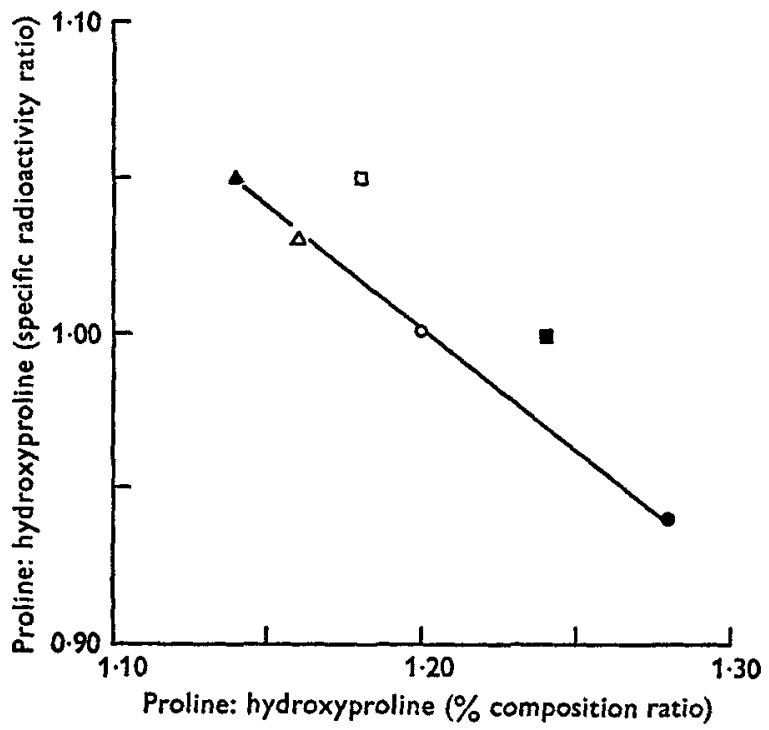

Fig. 2. Relationship between specific radioactivity and percentage composition ratios for proline:hydroxyproline in collagen of folic acid-deficient and control groups of rats given intraperitoneally $0.2 \mathrm{mCi} \mathrm{L-}\left[\mathrm{G}-{ }^{3} \mathrm{H}\right]$ proline. $O$ group $\mathrm{I}, 0$ group $2, \triangle$ group $3, \Delta$ group 4 , $\square$ group $5 \mathrm{a}, \square$ group $5 \mathrm{~b}$.

Table 5. Specific radioactivities of proline and hydroxyproline in aortic elastin from folic acid-deficient and control groups of rats given intraperitoneally $0.2 \mathrm{mCi}$ L- $\left[G-{ }^{3} H\right]$ proline $/ 100$ g body-wt

\begin{tabular}{|c|c|c|c|c|c|}
\hline \multirow[b]{2}{*}{ Group* } & \multirow[b]{2}{*}{$\begin{array}{l}\text { Proline: hydroxyproline } \\
\text { (\% composition ratio) }\end{array}$} & \multicolumn{2}{|c|}{$\begin{array}{l}\text { Specific radioactivity } \\
\text { (counts/min per } \mu \mathrm{mol})\end{array}$} & \multirow{2}{*}{\multicolumn{2}{|c|}{$\begin{array}{c}\text { Proline: hydroxyproline } \\
\text { (specific radioactivity } \\
\text { ratio) } \\
\text { Mean }\end{array}$}} \\
\hline & & Proline & $\begin{array}{l}\text { Hydroxy- } \\
\text { proline }\end{array}$ & & \\
\hline $\begin{array}{l}\text { I } \\
2 \\
3 \\
4\end{array}$ & $\begin{array}{l}6 \cdot 2 \\
6 \cdot 4 \\
6 \cdot 6 \\
6 \cdot 3\end{array}$ & $\begin{array}{r}212 \\
79 \\
\times 69 \\
74\end{array}$ & $\begin{array}{r}298 \\
6 \mathrm{I} \\
124 \\
61\end{array}$ & $\begin{array}{l}0.71 \\
1 \cdot 29 \\
I \cdot 27 \\
1 \cdot 21\end{array}$ & $\begin{array}{l}0.98 t \\
1.25 t\end{array}$ \\
\hline $\begin{array}{ll}\text { Folic } & 5 \mathrm{a} \\
\text { acid-deficient } & \mathrm{b}\end{array}$ & $\begin{array}{l}6 \cdot 3 \\
6 \cdot 1\end{array}$ & $\begin{array}{l}74 \\
51\end{array}$ & $\begin{array}{l}56 \\
27\end{array}$ & $\begin{array}{l}\mathrm{r} \cdot 32 \\
\mathrm{r} \cdot 89\end{array}$ & $\mathrm{I} \cdot 6 \mathrm{I}$ \\
\hline & $\begin{array}{l}* \text { For details, } \mathrm{s} \\
\dagger \text { Mean value } \mathrm{f} \\
\ddagger \text { Mean value } \mathrm{f}\end{array}$ & $\begin{array}{l}\text { Table I. } \\
\text { groups I } \\
\text { groups } 2\end{array}$ & & & \\
\hline
\end{tabular}

suggests that there is a slight but genuine increase in this ratio in these animals. Nevertheless, the increase is only marginal, indicating that there is synthesis of a collagen, in the folic acid-deficient rats, in which the level of hydroxylation of proline may be reduced by about $3-4 \%$.

Incorporation of $L-\left[G^{3} H\right]$ proline into aortic elastin. The results are presented in Table 5. As for collagen, the specific activity values in the pair-fed control groups indicate a reduced synthesis of elastin attributable to inanition, and values for the folic acid-deficient group indicate a further reduction attributable direct to the vitamin 
Table 6. Incorporation of $\mathrm{L}-\left[\mathrm{G}-{ }^{3} \mathrm{H}\right]$ proline and the specific activity of proline in the hot trichloroacetic acid-insoluble residue of skin from folic acid-deficient and control groups of rats given, intraperitoneally, $0.2 \mathrm{mCi} \mathrm{L}-\left[\mathrm{G}_{-}{ }^{3} \mathrm{H}\right]$ proline/100 g body-wt

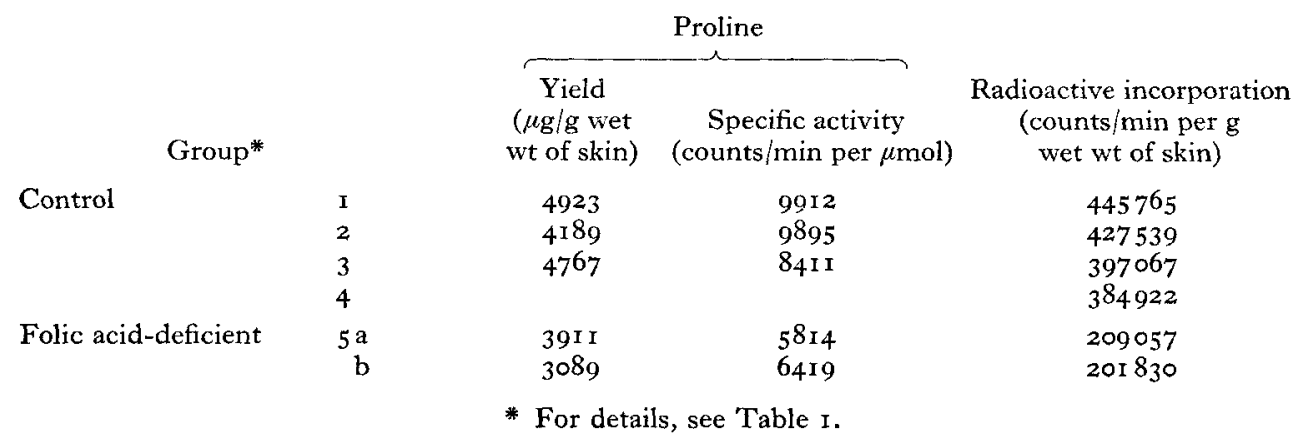

deficiency. The former reduction appears to be rather more marked and the latter rather less marked than the corresponding reductions in collagen synthesis. Again the specific radioactivity ratio values for proline:hydroxyproline suggest a very slight reduction in the hydroxylation of peptidyl proline to elastin hydroxyproline in the folic acid-deficient animals.

Incorporation of $\mathrm{L}-\left[\mathrm{G}-{ }^{3} \mathrm{H}\right]$ proline into the non-collagenous proteins of skin. The yield of material insoluble in hot trichloroacetic acid is shown in Table 3 . Colorimetric determination of hydroxyproline in this material, after hydrolysis, indicated that collagen represented only approximately $5 \%$ of the total weight. The lowest yield was obtained in the folic acid-deficient group.

The results of radioactive incorporation studies given in Table 6 again indicate an effect of both inanition and folic acid deficiency on the synthesis of the non-collagenous proteins contained in the hot trichloroacetic acid-insoluble material. In this instance, the reduction due to inanition appears to be only very slight and the reduction due to vitamin deficiency, in comparison, is marked.

The yield of proline from the hot trichloroacetic acid-insoluble material is lowest in the folic acid-deficient group (see Table 6), and this indicates that the relatively low yield of insoluble material in these animals (Table 3) can be accounted for partly as a reduced amount of non-collagenous protein. If dehydration of the skin occurs, as has already been suggested, then this reduction is even greater than suggested by the results in Tables 3 and 6 . The reduction is presumably a reflection of reduced synthesis coupled with a relatively high turnover rate.

\section{DISCUSSION}

The purpose of this work was to assess the effect of folic acid deficiency on collagen metabolism and in particular to determine whether tetrahydrofolate (or possibly related pteridines, assuming that a folate deficiency may be accompanied by a general pteridine deficiency) might normally be required in vivo for at least some of the 
hydroxylation of peptidyl proline in both collagen and elastin synthesis. In ascorbic acid deficiency, hydroxylation of collagen proline is apparently only slightly reduced and the most marked effect of the vitamin deficiency is an almost complete inhibition of collagen protein synthesis (Barnes et al. 1970). Although it has been proposed that this is most probably the result of impaired hydroxylation (Barnes \& Kodicek, 1972), the possibility also existed that collagen-proline hydroxylation in vivo involves primarily the participation of reducing agents such as reduced pteridines rather than ascorbic acid and that the inhibition of collagen-protein synthesis in scurvy implies some role for ascorbic acid in collagen metabolism other than one in hydroxylation.

Our results have shown that there is a marked inhibition of collagen-protein synthesis in the folic acid-deficient animals, part of which could be attributed to the inanition which accompanies the vitamin deficiency and the remainder to a more direct involvement of folic acid in collagen metabolism. Since the results indicated that there was also an inhibition of synthesis of non-collagenous skin proteins and aortic elastin (beyond that simply attributable to a reduced food intake), this suggests the more direct effect on collagen synthesis is not a specific one but reflects a generalized inhibition of protein synthesis in folic acid deficiency. Presumably this arises from the involvement of folic acid in both nucleic acid and amino acid metabolism (Stokstad \& Koch, 1967).

There appeared to be only a very slight increase in the specific activity ratio for collagen proline:hydroxyproline in the folic acid-deficient group, which is thought to indicate, therefore, only a very slight impairment of the hydroxylation of collagen proline. However, there is difficulty in assessing from this ratio alone a true measure of the impairment in collagen formation resulting from the absence in vivo of an essential hydroxylation factor. Thus, as mentioned above, Barnes et al. (1970) found in ascorbic acid deficiency that the ratio was increased only slightly and that the most marked effect, in vivo, of the vitamin deficiency was a large reduction in the over-all incorporation of radioactivity. This has been interpreted as an inhibition of collagen synthesis possibly secondary to impaired hydroxylation (Barnes \& Kodicek, 1972). It might be similarly argued that impaired hydroxylation arising from the absence of an essential co-factor in folic acid-deficient animals would also cause only a small increase in the specific activity ratio for proline:hydroxyproline but a large fall in collagen-protein synthesis. However, the increase in the specific activity ratio in folic acid deficiency appears to be even more slight than in ascorbic acid deficiency. Further, in view of the reduction in the synthesis of other proteins in folic acid deficiency (in contrast to the absence of such an effect in ascorbic acid deficiency), it is reasonable to assume that the reduction in collagen synthesis is part of a generalized reduction in protein synthesis rather than a reflection of impaired hydroxylation. It is considered that the very slight reduction only in collagen-proline hydroxylation in folic acid deficiency is insufficient to cause in itself any appreciable reduction in collagen-protein synthesis.

The values for specific activity "ratio proline:hydroxyproline in elastin confirm that the effect on hydroxylation of peptidyl proline in folic acid deficiency is only slight. A severe impairment in this instance would be expected to lead to a markedly increased 
ratio as observed for elastin synthesized by scorbutic guinea-pigs (Barnes $e$ t al. 1970). The slight impairment in the hydroxylation of peptidyl proline in folic acid deficiency could perhaps reflect a reduced level of hydroxylase as a result of the generalized reduction in protein synthesis (or conceivably of the enzymes involved in ascorbic acid synthesis).

Ascorbic acid may be required for maintaining folates and other pteridines in a reduced form, either direct (Stone\& Townsley, 1973) or through protection of the enzyme dihydrofolate reductase (Vilter, 1964; Kaufman, 1971; see also Nichol \& Welch, 1950; Broquist, Stokstad \& Jukes, 195I; Gabuzda, Philips, Schilling \& Davidson, I95I; Welch, Nichol, Anker \& Boehne, 195I; May, Hamilton \& Stewart, 1952). This raises the possibility that ascorbic acid may be required for the hydroxylation of peptidyl proline, in vivo, only indirectly by ensuring an adequate level of reduced folates (or related compounds) (see Nakashima, Suzue, Sanada \& Kawada, 1970) and that in ascorbic acid deficiency impaired hydroxylation of collagen proline is the result of a secondary folate deficiency (see Cox, 1968). Since, however, the hydroxylation of peptidyl proline appears to be little affected in folic acid deficiency, it may be concluded that tetrahydrofolate is not essential for this hydroxylation in vivo. The results support the view that ascorbic acid participates direct in the hydroxylation of peptidyl proline in vivo; as has been clearly demonstrated in the cell-free system (Hutton et al. 1967), thus permitting adequate hydroxylation in folic acid deficiency (see Priest $\&$ Bublitz, 1967 ). However, it should be borne in mind that although the rats in this study were clearly folate-deficient, it is not possible to conclude whether they were necessarily deficient in unconjugated pteridines (see Brown, I971).

The results of this study, although indicating that tetrahydrofolate is not essential for the hydroxylation of peptidyl proline, do not exclude the possibility, arising from the known ability of tetrahydrofolate to participate in this hydroxylation in vitro (Hutton et al. 1967), that in the normal situation in vivo when both ascorbic acid and folate are present, the latter may share in some measure the role of reducing agent in the hydroxylation nor do they exclude the possibility that a folate deficiency, secondary to ascorbic acid deficiency, may be a contributory factor in the inhibition of hydroxylation in scurvy.

The authors thank Dr E. Kodicek for the provision of facilities to J. G. A. J. H. to work in this laboratory, and for his helpful advice and encouragement. Our thanks are also due to Mr B. J. Constable for advice on the Technicon AutoAnalyzer, to $\mathrm{Mr} \mathrm{S}$. G. Impey for invaluable assistance with the care of animals and to the 'Neil's Stensen Stichting' for financial support (to J.G.A.J.H.). This work was submitted by J.G.A.J.H. as part of the requirements for the Diploma in Nutrition of the University of Cambridge. 


\section{REFERENCES}

Barnes, M. J., Constable, B. J. \& Kodicek, E. (1969). Biochem. F. Ir3, 387.

Barnes, M. J., Constable, B. J., Morton, L. F. \& Kodicek, E. (I970). Biochem. f. 119, 575.

Barnes, M. J. \& Kodicek, E. (1972). Vitams Horm. 3o, r.

Bergman, I. \& Loxley, R. (1963). Analyt. Chem. 35, I961.

Broquist, H. P., Stokstad, E. L. R. \& Jukes, T. H. (I95 I). F. Lab. clin. Med. 38, 95.

Brown, G. M. (197I). Adv. Enzymol. 35, 35 .

Clegg, J. W. \& King, E. J. (1942). Br. med. F. ii, 329.

Cox, E. V. (1968). Vitams Horm. 26, 635.

Craig, L. C., King, T. P. \& Stracher, A. (1957). F. Am. chem. Soc. 79, 3729.

Gabuzda, C. J., Philips, G. B., Schilling, R. F. R. \& Davidson, C. J. (I95I). 7. clin. Invest. 3x, 756.

Gould, B. S. (1970). In Chemistry and Molecular Biology of the Intercellular Matrix Vol. I, p. 43 I.

[E. A. Balazs, editor]. London and New York: Academic Press.

Hautvast, J. G. A. J. \& Barnes, M. J. (I972). Int. Congr. Nutr. IX, Mexico City, Abstr.

Herbert, V. \& Bertino, J. R. (1967). In The Vitamins Vol. 7, 2nd ed., p. 243 [P. Gyorgy and W. N. Pearson, editors]. New York and London: Academic Press.

Hutton, J. J., Tappel, A. L. \& Udenfriend, S. (1967). Archs Biochem. Biophys. 118, 231.

Ikeda, M., Fahien, L. A. \& Udenfriend, S. (I966). F. biol. Chem. 241, 4452.

Kennedy, J. F. (1969). Experientia 25, 1120.

Kaufman, S. (197I). Adv. Enzymol. 35, 245.

Kodicek, E. \& Carpenter, K. J. (1950). Blood 5, 522.

Lovenberg, W., Bensinger, R. E., Jackson, R. L. \& Daly, J. W. (197I). Analyt. Biochem. 43, 269.

May, C. D., Hamilton, A. \& Stewart, C. T. (r952). Blood 7, 978.

Nakashima, Y., Suzue, R., Sanada, H. \& Kawada, S. (1970). $¥$. Vitam. 16, 276.

Nichol, C. A. \& Welch, A. D. (1950). Proc. Soc. exp. Biol. Med. 74, 52.

Priest, R. E. \& Bublitz, C. (1967). Lab. Invest. 17, 37 1.

Prockop, D. J. (1970). In Chemistry and Molecular Biology of the Intercellular Matrix Vol. x, p. 335 [E. A. Balazs, editor]. London and New York: Academic Press.

Rabinowitz, J. C. \& Tabor, H. (1958). F. biol. Chem. 233, 252.

Shiota, T. (1971). In Comprehensive Biochemistry Vol. 21, p. II I [M. Florkin and E. H. Stotz, editors]. Amsterdam: Elsevier.

Stokstad, E. L. R. (1968). Vitams Horm. 26, 443.

Stokstad, E. L. R. \& Koch, J. (I967). Physiol. Rev. 47, 83.

Stone, K. J. \& Townsley, B. H. (1973). Biochem. F. 13r, 6 I r.

Tabor, H. \& Wyngarden, L. (1958). F. clin. Invest. 37, 824.

Udenfriend, S. (1 970). In Chemistry and Molecular Biology of the Intercellular Matrix Vol. I, p. $37 \mathrm{I}$ [E. A. Balazs, editor]. London and New York: Academic Press.

Vilter, P. W. (1964). Medicine, Baltimore 43, 727.

Welch, A. D., Nichol, C. A., Anker, R. M. \& Boehne, J. W. (r951). F. Pharmac. exp. Ther. ro3, 403. 